\title{
Transatlantica
}

Revue d'études américaines. American Studies Journal

\section{Expect the Unexpected: My Little Pony: Friendship is Magic and the Creation of a Double Audience}

\section{Isabelle Licari-Guillaume}

\section{(2) OpenEdition}

\section{Journals}

Electronic version

URL: https://journals.openedition.org/transatlantica/14963

DOI: 10.4000/transatlantica. 14963

ISSN: 1765-2766

\section{Publisher}

Association française d'Etudes Américaines (AFEA)

\section{Electronic reference}

Isabelle Licari-Guillaume, "Expect the Unexpected: My Little Pony: Friendship is Magic and the Creation of a Double Audience", Transatlantica [Online], 2 | 2019, Online since 01 October 2020, connection on 31 January 2023. URL: http://journals.openedition.org/transatlantica/14963 ; DOI: https://doi.org/ 10.4000/transatlantica.14963

This text was automatically generated on 31 January 2023.

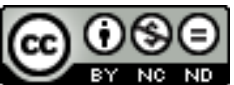

Creative Commons - Attribution-NonCommercial-NoDerivatives 4.0 International - CC BY-NC-ND 4.0 https://creativecommons.org/licenses/by-nc-nd/4.0/ 


\title{
Expect the Unexpected: My Little Pony: Friendship is Magic and the Creation of a Double Audience
}

\author{
Isabelle Licari-Guillaume
}

\section{Introduction}

1 This article deals with the 2010 reinvention of Hasbro's My Little Pony, which corresponds to the $4^{\text {th }}$ generation of the popular brand. First introduced in 1982-1983, My Little Pony is a "commercial transmedia supersystem" (Kinder 38), that is to say a franchise built around characters and narratives that span several media, from toys to TV shows to comic books. The $4^{\text {th }}$ generation was based on the animated TV show developed by Lauren Faust in 2010, My Little Pony: Friendship is Magic (which, for the sake of conciseness, I will refer to as "MLP: FiM"), through a partnership between Hasbro Studios and production company DHX Media. The show aired weekly on The Hub, a 2010 cable / satellite television channel owned in part by Hasbro that was re-branded as Discovery Family in 2014.

The first season of Friendship is Magic premiered on the first day of The Hub's broadcast, on 10 October 2010, and was scheduled each Friday at 1:30 PM Eastern Time (10:30 AM Pacific Time). In 2011 Season 2, also comprising 26 episodes, moved to the Saturday morning timeslot, where the show has remained ever since. Faust's ponies were visually quite different from those of the previous generations, with a larger head-tobody ratio and big eyes that sat low in rounder faces; but in other respects, her reboot aligned with the franchise's traditional values of wholesome fun and girly innocence.

With its cute, colorful design, MLP: FiM was meant to appeal to a target audience of girls aged 2 to 11 (Pollack n. p.), but also to the (presumably female) adults who might be watching the show with them: according to Vara and Zimmerman, "an executive told investors the remake was for 'the three- to six-year-old girl and her mom, who has fond memories of [earlier versions of] My Little Pony from her childhood"' (Vara and 
Zimmerman n. p.). This strategy of co-viewing (Griffiths n. p.) proved successful, and the series steadily gained viewers through seasons 1 and 2, with the two-parter "A Canterlot Wedding" (season 2, episodes 25 and 26) becoming the most successful program ever to air on The Hub ("Hub TV Network" n. p.).

Thanks to its popularity, MLP: FiM is currently in its ninth season ${ }^{1}$ and has been adapted into comics, video games, toys, collectibles, and an array of lifestyle items bearing the series' logo or characters. The comic book, published by IDW, has been particularly successful: "the first issue sold over 100,000 copies, and by October 2013, the series as a whole had sold over a million copies" (Kashtan 114). Overall, these widespread licensing policies led to consistently high profits for Hasbro, and My Little Pony "had a record year in 2014, with more than $\$ 1$ billion in global retail sales" (Hasbro 6).

In news coverage, the MLP: FiM phenomenon garnered a fair amount of attention because of the development of an unexpected or "accidental" audience. To quote media scholar Claire Burdfield:

The accidental audience [...] refers to an audience that was not a part of the predicted audience and differs significantly from them demographically. It is accidental on the part of the television industry, as it was an audience they inadvertently appealed to with a specific programme. (Burdfield 128)

In this case, the unexpected audience is composed of predominantly male adults, who refer to themselves as "Bronies" (a portmanteau of "bro" and "pony," although women will also typically use the nickname, see Coder Brony 62). The community originated on 4chan, an image board dedicated to (among other things) manga and animation, after creator Amid Amidi posted an article criticizing the show as derivative. 4chan users proceeded to watch the first episode of the series with the intention of making fun of it, but many found themselves genuinely enjoying the show. Still, according to Lisa Hix, "most bronies [...] have zero interest in the Ponies that came before 'Friendship Is Magic,' the first three generations of the toy, or the two girly My Little Pony cartoon series that aired in the '80s and '90s" (Hix n. p.). The extent of the Brony phenomenon in the United States and abroad has made it quite noticeable, to the point that many newspaper features and academic articles devoted to My Little Pony tend to emphasize the series' adult audience ${ }^{2}$ over any other aspect. In other words, despite the series' very real success with children, what made it visible in the wider cultural scene was mostly its devoted adult fans.

6 Starting with the idea of an "unexpected" audience, which was widely echoed in discussions of the Brony phenomenon, ${ }^{3}$ I would like to explore the notion of expectation. Hans Robert Jauss first suggested that cultural analysis should focus on reception and account for the reader's horizon of expectation, that is to say her previous knowledge of genre, pre-existing texts, and the role of fiction, which form the standard against which the new text is received (Jauss 49). In the context of contemporary fan culture, scholars such as Henry Jenkins have underlined the importance of audience involvement in the meaning-making process-how viewers project expectations onto the text and participate in creating them. However, we must also consider cultural producers' expectations regarding their audience-that is to say, the twofold intentionality emanating from corporations and individual creators, both of whom pursue specific social and economic goals. As we shall see, viewers' expectations and creators' intentions both play a part in the network of determinations that shaped MLP: FiM. 
7 In the first part of this essay, I discuss the guidelines imposed by Hasbro in terms of corporate branding and moral control over what children view. I subsequently move to the values that guided the initial development of MLP: FiM, specifically-but not exclusively-through the testimony of Lauren Faust, whose explicit goal was to create a show that would have a positive impact on girls' lives. Finally, I return to the notion of an unexpected audience to show that the viewers' demographics is in fact consistent with some of the creators' intentions, and even took an active part in shaping the series.

\section{Corporate expectations: profitability through brand development}

8 In today's mainstream entertainment industry, the creation of any TV or comic book episode is an inherently collective process and, as such, should be viewed as a compromise between multiple agents with potentially conflicting agendas. For the sake of clarity, however, I have broadly divided creative input into two categories: preestablished, external requirements (imposed by Hasbro) and internal storytelling decisions (made by show developers, writers, and animators). In this section, I consider the corporate-devised framework show developers had to follow while creating MLP: FiM.

9 Friendship is Magic's initial raison d'être was to support Hasbro's commercial development as a brand. In its shareholder address, the company retrospectively confirms that "as evidenced by the success of MY LITTLE PONY, TRANSFORMERS and MARVEL properties, it is clear that stories are differentiating brands, and industry data supports this trend" (Hasbro 5, capitals in original). In other words, the development of narratives that can be associated with the toys in young consumers' minds is seen as an efficient way to reinforce the toys' appeal, and TV is the ideal medium for such stories.

This strategy is not new: TV has been used in toy advertising since the 1950s (Kline 146) and the development of "commercial fiction" to support sales became prominent in the 1980s. That was "when Reagan made new appointments to the Federal Communications Commission (FCC) which led to de facto deregulation of children's television" (Kline 176). In fact, the original My Little Pony series, created in 1986 (though the toys themselves had been available since 1982-1983) was among the most prominent representatives of this trend. As David Buckingham argues, My Little Pony, along with other 1980s titles such as He-Man, Transformers, Teenage Mutant Ninja Turtles, or Smurfs, was specifically targeted by critics because of its explicit connection to merchandising:

For critics of the most recent animation series, however, the crucial concern would seem to be that merchandising is no longer a "secondary" activity, but the primary one. Toy manufacturers, for example, are no longer involved as secondary licensees "exploiting" the success of an established program. On the contrary, they are now involved in producing (or at least commissioning) the programs; and, it is argued, crucial decisions about form and content, about the characters and narrative situations, are now being made primarily with a view to their potential for launching new products. (Buckingham 157)

With the 2010 reboot, My Little Pony's nature as a "program-length commercial" (Greenfield et al. 238) was, from the outset, seen as damning evidence that the show could not be good. For example, in his 2010 article, Amid Amidi claims that My Little Pony embodies the death of creator-driven animation-a development in which Lauren 
Faust herself had played an important part through her involvement in the 1990s series The Powerpuff Girls: "Watching names like Rob Renzetti and Lauren Faust pop up in the credits of a toy-based animated series like My Little Pony is an admission of defeat for the entire movement, a white flag-waving moment for the TV animation industry" (Amidi n. p., my emphasis). However, the popular success of the series and the many awards it has received within the animation industry clearly questions the validity of Amidi's dichotomy between, on the one hand, "creator-driven" content (which he equates with quality) and, on the other hand, commercial animation (which is implicitly deemed derivative and stereotyped, especially when, like My Little Pony, it targets girls). Amidi's vision is marked by a romantic conception of the creator as an all-powerful auteur, motivated only by the artistic value of his or her work, and detached from worldly concerns which would otherwise mark it as illegitimate. With MLP: FiM, Faust and her team of writers and animators proved that the many constraints of a commercial franchise could in fact be successfully integrated into a story that played with-and sometimes subverted-the stereotypes associated with girls' shows.

What did change between the 1980s series and the 2010 reboot was Hasbro's focus on the quality of their show, as shown by a reversal of their priorities: although toy sales are still the main source of revenue supporting the show itself, in the case of MLP: FiM, the toys were based on show developer Lauren Faust's designs, whose first goal was to preserve the internal consistency of the series. In many cases, toy designers had to work with what animation designers gave them, not the other way around, suggesting that the commercial nature of the show was compatible with an ambition to develop quality animation.

This does not mean that the series' visual design was entirely free from corporate requirements. In an interview for the fan website Equestria Daily, Lauren Faust confirms that during the production of the first season, Hasbro asked for several cosmetic changes, such as "visual tweaks to locations that had playset potential and changes to some of the names of locations and side characters to make them more "salable" (Tekaramity n. p.). She adds:

Hasbro's input came mostly when a location had potential to be a playset. Rarity's Carousel Boutique was revised a few times. There were also times when they were working on a toy they wanted to have featured in the show. The hot air balloon was introduced this way. Often they'd ask for a location beforehand, like a schoolhouse, so we could design it first. They were pretty great about letting us decide how to use these locations in context of the story so it didn't just seem to come out of nowhere. (Tekaramity n. p.)

What Faust describes is a two-way collaboration between Hasbro's toy department and Faust's animation team, seeking to preserve the consistency of Faust's fiction (and thus its attractiveness) with an eye to the promotion of toy sales. Thus the series' commercial function, although crucial, is embedded within a broader perception that investing in a well-told story, with strong characterization, fluid animation, and excellent voice acting is ultimately the most efficient way to boost sales. After Faust stepped down at the end of season 2 in 2012, the series continued along the same lines: although it retained its attention to story and characterization, it also introduced new characters that were obviously designed to be sold as a new range of toys, such as the Crystal Ponies, and updated the designs of some of the main characters, encouraging children to acquire the newer version. 


\section{Educating children}

13 Beyond the vision of the child-as-consumer, which is clearly prominent in Hasbro's marketing strategies, lies another way of looking at childhood as inherently vulnerable and in need of education and protection, which can be called the child-as-innocent. Indeed, the series' development was constrained by its initial status as an E/I (educational and informational) program. ${ }^{4}$ The Federal Communications Commission (FCC), which supervises E/I programs, states that they are "specifically designed to serve the educational and informational needs of children 16 years of age and under, including the child's intellectual/ cognitive or social/emotional needs" (Federal Communications Commission n. p.). The guideline's rather general wording implies both prescriptions and restrictions relative to the type of characters, situations, and events that may be depicted on screen. This in turn is linked with a specific view of childhood and its position with respect to the adult world. As Buckingham puts it: "adult definitions of childhood are thus simultaneously repressive and productive. They are designed both to protect and control children [...] they are seeking not just to prevent certain kinds of behaviour but also to teach and encourage others." (Buckingham 12)

MLP: FiM's educational claim, however, falls more in the area of the "social / emotional" development of children: the series is based on the eponymous "magic of friendship", and promotes consensually positive values such as good behavior, cooperation, and hard work, with each character embodying a specific quality (honesty, generosity, kindness, loyalty, laughter). Each episode ends with a moral in the form of a letter from the main characters to Princess Celestia, the benevolent ruler of the land, in which the characters explain what they have learned. Most of these "friendship lessons" stress the values of respect, tolerance, or the need to overcome prejudice: for example, "Bridle Gossip" ends with the idea that one should "never judge a book by its cover. Someone may look unusual, or funny, or scary. But you have to look past that and learn who they are inside" ("Bridle Gossip" 00:20:31-00:20:40). In this sense, MLP: FiM belongs to a long line of educational cartoons that "focus [...] on the pre-social behaviours of children, [...] providing lessons to children on appropriate relations with peers and adults" (Lapierre 100).

15 MLP: FiM's friendship lessons are "educational" in the sense that they encourage children to follow certain rules and behave in a certain way. However, E/I standards are not only about promoting values, they also involve strict guidelines about what children should not be shown, for fear that they might imitate it. Adult expectations of what is appropriate for young viewers do in fact have a very concrete impact on show development, as Lauren Faust explains:

Character behavior that was considered OK in shows I'd worked on previously was suddenly considered "inappropriate for children" in My Little Pony. Something as mild as Rainbow Dash calling Twilight an "egghead" in "Fall Weather Friends" [season 1 episode 13] was treading a very delicate line. Even the whole concept of her and Applejack cheating was worrisome to some. (Tekaramity n. p.)

These specific examples show how the language and behavior depicted in the show (as well as in other transmedia narratives) are kept under strict control. More importantly, they allow us to grasp how institutions such as the FCC view the relationship between children and audio-visual media: younger viewers are, they believe, likely to either imitate or be shocked by the behavior they see on television. Therefore, children need 
to be protected from potentially offensive material and at the same time deterred from using certain words or behaving in certain ways. Because of this double bind, and most of all because "it is very hard to predict what children will find disturbing or upsetting" (Buckingham 142), regulating agencies like the FCC provide networks and studios with strict self-censorship guidelines that ensure problematic material will simply not appear-as opposed to appearing in a way that might help children deal with it. Thus, the complexities of moral and social education are subsumed into the decision to erase material that does not fit adults' perception of what a child should do or see.

This contemporary strategy is, in essence, very similar to the measures adopted by the film industry in the 1930s with the Motion Picture Production Code (also known as the "Hays Code") and eventually by comic book publishers with the 1954 Comics Code. Although the context was of course very different, all these self-regulatory bodies focused on forbidding and erasing potentially offensive material in order to dodge the risk of censorship or boycotts, which demonstrates a continuity, from the 1950s to the early twenty-first century, in the way adults perceive children's interaction with visual media and the strategies they implement to mitigate their potentially negative effects on sales. This is symptomatic of what Shirley Steinberg and Joe Kincheloe call "the positivist view of childhood [which can] only be maintained by constant social regulation and surveillance of the young" (Steinberg and Kincheloe 6).

However, I would argue that within this framework, the show itself endeavors to enable children to think of themselves as adults in the making, by emphasizing independence and self-realization. As I shall demonstrate in the next section, MLP: FiM provides its viewers with a safe space in which traditional asymmetrical relationships between adults and children, but also between men and women, are (temporarily) put on hold.

\section{Creator expectations: positive social impact through girls' entertainment}

In an industry that "too often [...] refuses to challenge patriarchal power structures or provide alternative vantage points on the world" (Steinberg and Kincheloe 37), MLP: FiM encourages critical engagement with reality by creating stories that allow children to reflect on gender roles. The decision to follow an all-female cast under a matriarchal social order endows female characters with traits that would typically be attributed to males in other cartoons (for example, sports-loving, competition-oriented Rainbow Dash is a girl, despite many viewers' initial assumption to the contrary, see Cider Float n. p.). Thus, the series encourages viewers to question stereotypes and broaden the spectrum of behaviors deemed compatible with girlhood. This ambition resonates with the fact that Lauren Faust, who describes herself as a feminist, worked with the explicit goal of creating "quality entertainment for girls" (Tekaramity n.p.). The "educational" value of MLP: FiM lies also in its ability to question gender stereotypes and promote young girls' agency. In so doing, it interrogates the audience's identification with social constructs attached to gender, and also age.

Just as Bronies, i.e. male fans, are central in the media's treatment of MLP: FiM, the series is frequently analyzed by critics as a site of potential renegotiation of male gender norms. For example, Mikko Hautakangas explores the ways in which Bronies express sincere affection for the show, in what he sees as a display of "neo-sincerity," 
which is at odds with dominant norms of masculine behavior where boys and men are expected to keep such feelings in check. "Bronies feel that they implement elements into their gender performance that are normally excluded from the heterosexual male repertoire-such as colorful joy, flamboyant playfulness and open-armed friendship," he concludes (Hautakangas 117). I would argue, however, that it is only possible to use My Little Pony to question male gender norms insofar as the series is first and foremost an indictment of female stereotypes. "Colorful joy" and "open-armed friendship" appear palatable to men precisely because the creators' intention was to present them as positive human values, rather than as constrictive female behavior patterns.

21 Hautakangas' adjective "colorful" is particularly significant, because the use of "feminine" colors in MLP: FiM was an explicit concern in the development of the project, a telling example of the show's specific treatment of female-associated elements. Lauren Faust stated in various interviews how intent she was on using a broad array of colors for her main characters, instead of restricting herself to stereotypically "girly" hues: "Pink, purple, and turquoise. Fushia [sic]. This horrible combination. It's like, every girl toy is this horrible combination of colors and it drives me bonkers. For me, pink has become symbolic of the limitations placed on girls and women" (S.A., n. p., my emphasis). To deal with the issue of color-coding Faust obviously did not reject bright tones. Instead, she reclaimed "feminine" colors by refusing the limitations to stereotypical pink, purple, and turquoise. Her answer was a diversified color palette: while Twilight Sparkle is purple, and Pinkie Pie is (as her name suggests) a rather frank shade of pink, the other four main characters have slightly more genderneutral colors such as white, yellow, orange, and light blue. The same intention later drove the coloring team's efforts, leading Faust to state that "the colorists achieved something that is definitely feminine, but unique in that it is still extremely appealing, pleasant, and devoid of cooties, if you know what I mean" (Tekaramity n. p.).

Faust's mention of "cooties," a playground term boys use to reject contact with girls, is symptomatic of the experience that led to the creation of My Little Pony: Friendship is Magic. The attempt to fight the stigma associated with girliness is grounded in Faust's keen awareness of the systemic devaluation of girlhood, and her own experience as a little girl playing with older generations of My Little Pony toys and realizing that her interest in them was systematically ridiculed (Tekaramity n. p.). In fact, the My Little Pony franchise's history bears witness to this rejection. As evidenced by Sherilyn Connelly, the franchise's reception from the 1980s on was fraught with rampant misogyny: commentators insisted on expressing disgust at its saccharine femininity and often condemned it as a hopelessly cynical effort to sell more toys, while equally mercantile but less girly series such as Transformers received much more neutral reviews (Connelly 68).

The key to Faust's approach is to assert the diversity behind girlhood: the ubiquitous equation "pink = girl" does not function in MLP: FiM because "girl" is never depicted as a monolithic concept. Indeed, the decision to feature an all-female cast allows Faust to sidestep the infamous "Smurfette Syndrome", a notion coined by Times journalist Katha Pollitt in 1991 and taken up by contemporary feminist media critics to point out that many children's stories in popular media include only a minority of female characters, thereby effectively typecasting "female" as a fixed and monolithic trait (Pollitt n. p.). different personalities and interests, demonstrating that there are many ways to be a 
girl. Perhaps more importantly, Faust's guidelines for the show insisted that none of the ponies should be a stereotype: although each is undeniably a "type" (the nerd, the shy one, the country girl, etc.), they also exhibit traits that complexify their personalities. Nowhere is this more visible than with the character of Rarity, the sophisticated fashionista. In "A Dog and Pony Show" (season 1 episode 19), Rarity is kidnapped by the villainous Diamond Dogs who want to take advantage of her gemfinding abilities. The other characters embark on a rescue mission, but what begins as a generic damsel-in-distress plot takes an unexpected turn when Rarity turns out to be quite able to fend for herself: her determination to resist through all the means at her disposal (from dignified complaint to lachrymose whining) eventually leads to her release from the comically exhausted dogs. The moral is explicitly spelled out by Twilight in the conclusion of the episode: “Just because somepony ${ }^{5}$ is ladylike doesn't make her weak. In fact, by using her wits, a seemingly defenseless pony can be the one who outsmarts and outshines them all" ("Dog and Pony Show" 00:21:06-00:21:16). This episode is emblematic of Faust's insistence on the reappraisal, rather than rejection, of traditionally feminine traits: Rarity may be obsessed with her looks, but her fussiness is combined with a true artistic sensitivity and enviable social skills.

\section{Animality, age, and the redefinition of girlhood}

While the emphasis on female protagonists had been a hallmark of the series since the 1980s, Friendship is Magic made it a political statement by developing a matriarchal fantasy universe that eschews gender roles. Crucially, Generation 4 did not involve human protagonists in the way the 1980s series had: viewers are invited to identify not with a little girl playing with fantastic creatures, but with the creatures themselves. I would argue that this decision helps question the gender differentiation of play; as Steinberg and Kincheloe point out, "boys [...] become one with their toys, while girls take care of theirs-ever the adoring spectators of their dolls in girl commercials" (39). Tellingly, Marsha Kinder recalls how her son stopped playing with My Little Pony toys after seeing a commercial "where they were being fondled exclusively by little girls (in hyperfeminine clothes) who combed their colorful manes" (Kinder 50). In Faust's version of the show, there is no "adoring spectator" included in the diegesis to instruct viewers on how they should interact with the ponies; instead of attention, the characters become the recipients of girls' identities.

The animal protagonists' anthropomorphism is significant in the reappraisal of girlhood conveyed by the show. As Venetia Laura Delano Robertson suggests:

Quasi-human figures release us from our "webs of association," our human confines, and enable a self-reflexive experience free from the strictures of gender, age, race, and, presumably, species. In summary, as anthropomorphic animals, the ponies provide both escapism from, and a reflection of, the humanity of the viewer.

(Robertson 12)

Interestingly, Robertson mentions age as one of the specific markers of identity which are invisibilized in anthropomorphic animals, but she seems to miss the point that the protagonists' agelessness is in fact a crucial factor in MLP: FiM's redefinition of girlhood. Lauren Faust makes it clear that "the ponies' ages were left intentionally undefined. [...] I like to think of them as having maturity levels anywhere between 12 and 18" (FyreFlye n.p.). Faust's mention of "maturity levels" apparently refers to emotional maturity, and from this point of view it makes sense that the characters should be the 
equivalent of teenagers; they are role models, older-sister figures showing the viewers the value of friendship, confidence, and other important morals associated with childhood. The fact that two of the main characters (Applejack and Rarity) have younger sisters who attend what resembles primary school also supports this reading.

However, if we look at these characters' social status, a different picture emerges: all of them lead independent lives, they are explicitly autonomous from their parents, and some of them display high levels of professional qualification (Rarity is a fashionista who owns her own boutique and is variously depicted designing new models, managing stock, and opening a second retail store in another city). Despite her status as a student of magic, Twilight Sparkle is not so much an equine high-schooler as the equivalent of a post-grad, who conducts autonomous research in specialized libraries under the sporadic supervision of her mentor. In other words, the agelessness afforded by anthropomorphic animals enables the characters to combine the agency and material independence of a grown woman with the need for emotional nurturing that is distinctive of childhood and adolescence.

More importantly perhaps, this deliberate blurring of age allows the show to eschew the one question that would be at the core of the narrative if Twilight, Rarity, and the others had been human twentysomethings: romantic involvement. MLP: FiM deals with friendship, not love, and although it includes several (heterosexual) couples such as Mr. and Mrs. Cake or Cranky Doodle and Mathilda, and occasionally portrays romantic attraction (between the newlywed Cadance and Shining Armor, or, as comedy, between Cheerilee and Big McIntosh in "Hearts and Hooves Day"), none of the main characters is ever given a love interest. Rarity's short-lived desire to "meet her prince" in the fairytale-inspired episode "The Best Night Ever" is promptly quelled as Prince Blueblood turns out to be vain, rude, and self-centered.

Overall, the main characters are set in pre-sexual blissful ignorance of the opposite sex, even as other aspects of their personalities cast them as young adults. This contrasts not only with a majority of shows aimed at young girls and featuring adolescent protagonists, but even with MLP: FiM's own spinoff movie, Equestria Girls, in which Twilight travels to a parallel universe where she becomes a human high-schooler, meets human versions of her friends, and develops a romantic interest in a teenage boy. Thus, MLP: FiM uses animal characters to select the aspects show developers want to explore, outside the boundaries of what would seem believable or consistent if the characters were humans. Crucially, through emphasis on female friendship, individual development, and the celebration of diversity, they seek to nurture children's ability to think of girlhood as a non-restrictive category where individuals have value in themselves, not only through their relationships with boys. The series acts as a safe space for girls and an antidote to stereotypical depictions of female characters who are, on the whole, less numerous, less developed, and less interesting than the males. Although it does not directly challenge patriarchy and leaves unaddressed the specific issues of race and class in intersection with gender, MLP: FiM still efficiently resists the sexist representations that are pervasive in children's entertainment. 


\section{Beyond expectations: redefining audiences through practice}

In the previous section, I have shown how the anthropomorphic animals in MLP: FiM occupy a liminal space between childhood and adulthood, allowing the story to incorporate a reflection on gender. I now suggest that this elastic conception of the characters' age parallels the emergence of an audience that is not simply structured along fault lines of age or gender, but also reflects how audiences engage with the material they view or read.

Family-oriented movies, such as those by Pixar, often combine a storyline aimed at children with jokes that, in the words of Barbara Wall, "deliberately [exploit] the ignorance of the implied child reader and [attempt] to entertain an implied adult reader by making jokes which are funny primarily because children will not understand them" (Wall 35). This strategy is what Wall terms "double address". As demonstrated by Aaron Kashtan, double address plays an important part in the My Little Pony franchise (Kashtan 119), with many references to pop culture (for example, with the above-mentioned "Diamond Dogs," who are named after a David Bowie song) or, more importantly, specific elements of Brony fan culture. That is why Kashtan additionally suggests that the jokes may not be directed mainly to "parents" but rather to "adult fans" (121).

The term "adult fans" is in fact problematic when approximately a third of selfidentified Bronies are 17 or younger (Coder Brony 12). While they are obviously older than the age group initially targeted by the show, Bronies are not always adults; nor are they necessarily male, with a sizeable 20 percent minority of women. MLP: FiM's creators indeed construct two "model reader[s]" (Eco 68). However, their use of double address is not based on the opposition between children and grown-ups, but on the rift between those who simply consume MLP: FiM narratives by watching the show or reading the comics, and those who actively engage in online activities around it; between mere enthusiasts and actual fans-as defined not only by their degree of personal enthusiasm, but by their involvement in the creative and social dimension of fandom (Jenkins 1-2). In MLP: FiM, the story usually addresses the offline audience (mostly but not only composed of female children) while making jokes for fans who watch and discuss the show online (primarily but not exclusively male adults).

MLP: FiM stands out as an exceptional site for the discussion of such issues because its creators are largely influenced by online fandom. The first recorded example of the inclusion of fan discourse into the series occurred when showrunners Jason Thiessen and Lauren Faust, who frequently visited Internet forums and image boards dedicated to the show, decided to make Derpy a recurring character of the series. Derpy was originally a nameless background pony in the first episode, who caught the fans' attention because of an animation glitch that made her cross-eyed. She became a recurring object of interest among fans, which led to her inclusion in subsequent episodes. The writers' and animators' commitment to their Internet audience persisted through several seasons and eventually led to the (rather radical) decision to make episode 100 a tribute to the fandom: "Slice of Life" features many fan-favorite background characters and includes inside jokes that originated in the fandom. 

romanticized victory of fan enthusiasm over corporate agendas or as male adults' cultural appropriation of a show initially meant for little girls (since episode 100 would make very little sense to children, who presumably lack consistent access to MLP: FiM fandom). This debate ties in with conflicting views on the Brony phenomenon in general, and its relation to gender politics in particular: indeed, there has been much debate surrounding Bronies and what they tell us about gender constructs. While some argue that MLP: FiM has helped redefine, or at least question, hegemonic models of masculinity (Robertson; Hautakangas), others see Bronies as a group of adult males wielding their own privileged cultural position (Kirkland; Saintcheshire quoted in Jones 122). audience (young girls) and the unexpected one (adult males). And while issues of gender representation are crucially important to our understanding of the series, I suggest that they can also obfuscate the impact of media practices. The apparently clear-cut division between (male) Bronies and (female) children has less to do with who watches than how they watch. The Brony phenomenon appeared and thrived because of the Internet: people heard about MLP: FiM through websites and message boards; they watched the show and read the comics through streaming platforms, then proceeded to discuss it online. Of course, some of these Internet spaces are empirically known to be mostly male (e.g.4chan); yet the media fandom in general is "largely female" (Jenkins 1), and women are keen practitioners of fan art (on DeviantART) and fan fiction (on FanFiction.net). In this respect, I argue that what unites the MLP: FiM fandom is less the gender (or age) of its participants, than the homogeneity of their mediatic engagement with the franchise.

With My Little Pony, as with an increasing number of twenty-first-century franchises, we witness a blurring of the traditional limits between children's and adults' modes of engagement with the brand, its narratives, and the goods that are sold under its franchise-be they licensed goods or the very toys that preexisted the series. Steinberg attributes this change to the development of information media:

While a playful dimension of Internet usage promotes the blurring of distinctions between adults and children by promoting "juvenation," the "adultification" dimension of children's Internet activity is certainly important. (Steinberg 33)

Indeed, the Internet era has given new visibility to fan practices, many of which involve a playful approach to culture: fan art and fiction, toy collections and other forms of craft have thrived along with the online spaces and tools that helped fans produce and share their creations. Activities traditionally associated with child audiences are invested with a different value once they are shared through online communities. For example, MLP: FiM fans seem to have a strong interest in toys: more than 50 percent of self-identified Bronies purchased Hasbro toys at some point in the year 2014 (Coder Brony 68). Moreover, besides the MLP: FiM fandom, there is a substantial (in fact predominantly female) community of My Little Pony enthusiasts who focus on collecting and customizing toys from older generations of the franchise. According to Heljakka's analysis of adult toy play, Bronies engage with their toys in ways that involve some form of mediation (for example, through photoplay, which involves taking and sharing photos of one's ponies in specific locations), instead of focusing solely on the tactile and narrative dimensions that are typical of child's play (Heljakka 101). In this context, the same objects are connected to different practices and a given 
individual may progressively graduate from offline "child" play to online "grown-up" play.

In fact, one could even suggest that MLP: FiM creators encouraged fan appropriation by including elements which, intentionally or not, lend themselves to playful uses and replication. To understand this, we must consider the graphic style of the series. Despite being a US / Canadian production, MLP:FiM is very influenced by manga aesthetics, both in its visual style (large round eyes, small body-to-head ratio, colorful designs, etc.) and consumption patterns. Indeed, the series belongs clearly to what postmodernity philosopher Hiroki Azuma calls Otaku culture: a multimodal story in which various objects (comics, animated show, toys, merchandise) are tightly connected to one another and comprise gaps which viewers / readers can fill in by creating their own version of the story. MLP: FiM uses "elements of attraction" (Azuma 82) such as the flowing manes or the animal ears, which make the design of the series easily recognizable and endlessly replicable through computer or hand drawing. Since the series is animated with Flash, a broadly available technology, fans have produced a wealth of pony-related material, and all this fan-generated activity is at the core of what made MLP: FiM successful online.

In sum, the rise of MLP: FiM's "unexpected audience" becomes much less surprising when one thinks in terms of media and consumption practices, rather than identity. Of course, the two are closely linked; however, I would agree with Benjamin Woo's claim that "audiences" are an abstract notion unless they can be grounded in specific practices and contexts: "this shift in emphasis is crucial because practice is necessarily prior-in the sense of temporal or logical priority, not necessarily of importance-to identity" (Woo 65).

In the final section of this essay, I elaborate on the idea that MLP: FiM encourages the development of fan culture by looking at the series' depiction of nerds, defined broadly as individuals interested in science, computers, obscure or specialized knowledge, and, by extension, Internet culture. Nerdiness is a personality trait which is not limited to adults (famous nerds in kinderculture include Jimmy Neutron and Lisa Simpson) and allows us to move beyond the child / adult opposition. It is also strongly associated with maleness (although not with traditional, "alpha" masculinity) (Kendall 505; Jenkins 10), which makes it a useful theme for MLP: FiM's contestation of gender stereotypes.

\section{Growing up nerdy}

When Lauren Faust pitched her Friendship is Magic project to lead voice actress Tara Strong, she described the character of Twilight Sparkle as "a little bit nerdy but still someone you'd want to hang out with" (Malaquais 00:13:18). Indeed, as a socially awkward, clearly obsessive character, Twilight makes a convincing figurehead of nerd culture, and as such resonates with online fan communities at large: for example, she is consistently cited as being the character Bronies most identify with (Coder Brony 85). Also, because she is the story's central protagonist and her initial preference for books over people is emphasized in the very first episode-"I just need to be alone so I can study without a bunch of crazy ponies trying to make friends all the time!" ("Friendship is Magic Part 1" 00:16:28-00:16:32) -the nerd appeal of My Little Pony becomes obvious even for those who set out to watch the series ironically. Thus, 
Twilight's role in the acknowledgement of nerd culture may well be one of the reasons why it proved so successful with adult fans.

Lauren Faust's previous involvement in cartoons with cult status (Powerpuff Girls), her Internet-savviness, and her prominence on sites like DeviantArt mean she could easily qualify as a nerd. This in turn gave her the ability to nurture the fandom. Even in the early days when the Brony fandom was considered suspect or unsavory by the public at large, Faust was quick to respond in a positive manner by adopting the codes and practices of Internet culture-one example among many is her creation of an "OC" or "original character," that is to say a ponified version of herself that, like any other fan, she used as an avatar, and was notably featured alongside an exclusive interview at Equestria Daily (Tekaramity n. p.). Through her support of the fandom, Faust became a mother figure to the movement, relinquishing the traditional authorial posture to appear as an approachable public figure that fans treat with "worshipful deference" (Jenkins 24). This is indeed typical of the reconfigurations of authority implied by fan practices, which blur the boundary between creators and consumers, without entirely relinquishing the "author function" (Ribard and Foucault 39) of their objects. Indeed, these texts are still imbued with signs that construct and point towards the presence of an author (through metatextual references, recurrent stylistic features, legal mentions in end credits, etc.).

Nor is Faust the only member of the producing team in that situation. After she stepped down as show developer, other artists adopted a similar stance. Katie Cook, the first scriptwriter for the comic book series, is known for her investment in Star Wars fandom, and the codes that she uses to depict Twilight are clearly nerd-friendly. In "Neigh Anything," a very young Twilight and her babysitter Cadance bond over their obsession for lined stationary while working through intricate statistics. The two fillies' nerdiness is all the more striking as it takes place within a rather stereotypical plot in which Cadance and Shining Armor, a couple, tell about how they first met while still in high school. The story uses the generic tropes of high school romantic comedies and is told from two different points of view, first by Shining Armor (part 1), then Cadance (part 2). The first part plays the trope straight by depicting Shining Armor as the shy nerd who gets proverbial sand kicked in his face by a more macho rival. Shining Armor attends chess club, math club, and gaming club (as mentioned on the cover illustration of part 1) and enjoys games such as "Oubliettes and Ogres" or "HocusPocus: The GetTogether" (Cook and Price, 2013a 8; 2013b 11), which are obvious spoofs of table-top roleplaying game Dungeons \& Dragons and collectible card game Magic: The Gathering, two hallmarks of nerd culture.

However, in the second half of the story, Cadance and Twilight turn out to be equally, if not more, geeky-despite the fact that one is the typical prom queen and the other a very young child. For example, a kindergarten-aged Twilight asks: "Are you ready to take extensive notes on his likes and dislikes, to create several comparative charts about your popularity vs. his? Did you bring a label marker? Is your paper wide ruled or academy ruled?" To which Cadance defiantly answers: "I have 37 different colors of paper for my label marker. I always have an abacus with me just in case I need to calculate percentages for a pie chart. Wide-ruled paper is for foals. Let's do this." (Cook and Price, 2013b 4, emphasis in original) 


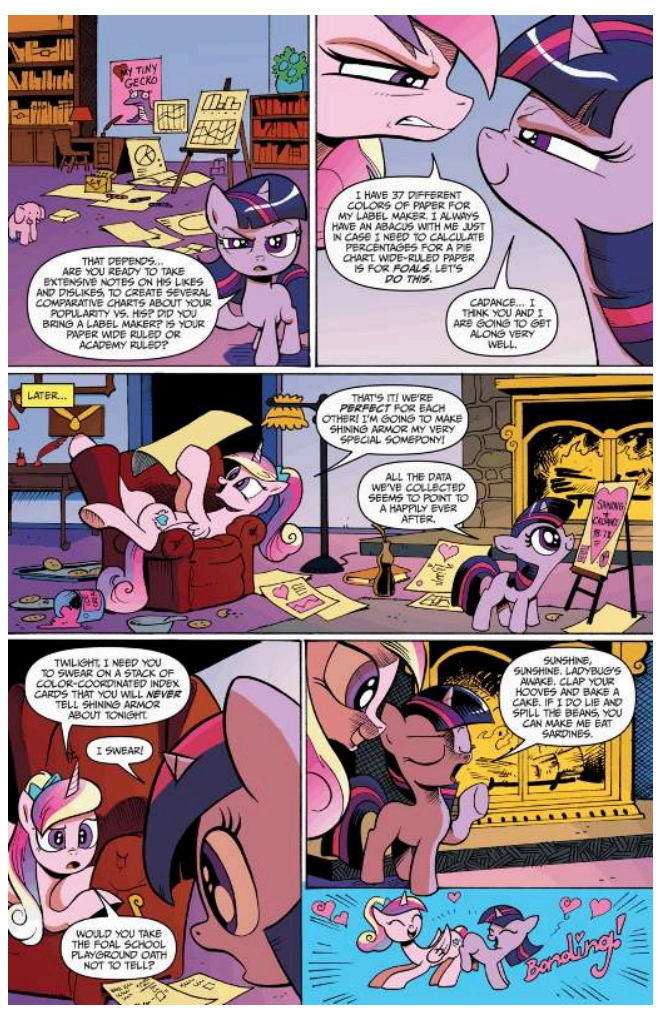

Figure 1: “Neigh Anything, part 2," My Little Pony: Friendship is Magic \#12, Oct. 2013 (Cook and Price, 2013b 4)

44 Accidentally, on the first panel of that page, readers get a glimpse at what seems to be Twilight's bedroom, containing a stuffed elephant, a paper board, and a poster with the title "My Tiny Gecko," which of course is a parody of My Little Pony itself. Such selfreferential jokes are frequent in Cook and Price's comic books, ${ }^{6}$ but in this case the suggestion that Twilight herself stands for My Little Pony fans is a clear indication of the type of audience Cook and Price expect or hope for. Twilight's status as a young female who is just as nerdy as her big brother but still enjoys girly toys might indicate that Cook and Price do not perceive Bronies and girls as mutually exclusive.

In other words, the importance given to nerd culture functions not only as a nod towards Bronies, but also, crucially, as a role model for the little girls who compose the primary audience. Twilight's love of books and science is not incompatible with her age (especially in the abovementioned sequence of the comic book) or gender; neither does it prevent her from having friends who enjoy different things. If anything, the opposition between "expected" and "unexpected" audience which is so often invoked to talk about My Little Pony tends to obscure the crucial point that the series itself encourages its audience to accept "unexpected" behaviors and respect each individual's need for self-realization, even when they do not align with one's tastes or values. Obviously, the fact that so many of the creative people involved are women with an interest in Internet fan culture (Lauren Faust and Katie Cook being but two examples) might explain the direction the show took: these women are writing things they would have enjoyed as children-or as Lauren Faust puts it, "my own inner eightyear-old was my personal focus group" (Tekaramity n. p.). 


\section{Conclusion}

Looking at My Little Pony: Friendship is Magic in terms of its creators' intentions allows us to move beyond the oppositional paradigm which posits a clear separation between the "expected" audience of young females and the "unexpected" fan base composed of adult males. In practice, divisions based on age and gender do not provide a satisfactory picture of how the franchise (television show, comic books, and movie) addresses its audience and what it expects of them. More convincing is the notion that MLP: FiM develops its own form of double address, where an additional layer of discourse will only be available to a specific group-not merely adults, as would usually be the case, but more generally people who are familiar with Internet popular culture and have mastered its codes. The show is aimed at young people through its focus on the development of positive social interactions, emotional well-being, and more specifically the encouragement of independence, creativity, and solidarity in girls and women. Yet it also casts Internet culture in a very positive light, presenting it as a valid way of life, and encourages viewers or readers to interact with the story in playful, creative ways.

In other words, the development of a fan community beyond the target audience can be seen partly as a consequence of the creative team's efforts to increase the appeal of girls' entertainment by making it less stereotyped, more universal, and to provide girls with a richer mental playground in which to flex their own creative muscles and engage with others. Redefining the audience has in fact led to the creation of a multimodal narrative that reaches far beyond its initial commercial target. But in point of fact, this redefinition was also partly caused by online participation, where fans inserted themselves into the creative process through their willingness to analyze, debate, and appropriate the franchise in innovative ways. The paradox may be that from this point of view, the younger audience members are the least visible of all-at least until they enter the spaces of fan sociability, whose forms of engagement with the material (drawing, telling stories, etc.) prolong those of childhood by recontextualizing them within a different social and cultural space.

\section{BIBLIOGRAPHY}

\section{Primary sources}

\section{Series episodes}

"Bridle Gossip." My Little Pony: Friendship is Magic, season 1 episode 9. Created by Lauren Faust. Written by Amy Keating Rogers. With Tara Strong (Twilight Sparkle). The Hub, December 2010.

"Dog and Pony Show (A)." My Little Pony: Friendship is Magic, season 1 episode 19. Created by Lauren Faust. Written by Amy Keating Rogers. With Tara Strong (Twilight Sparkle). The Hub, March 2011. 
"Friendship is Magic, part 1". My Little Pony: Friendship is Magic, season 1 episode 1. Created by Lauren Faust. Written by Lauren Faust. With Tara Strong (Twilight Sparkle). The Hub, October 2010.

"Slice of Life." My Little Pony: Friendship is Magic, season 5 episode 9. Created by Lauren Faust. Written by M.A. Larson. With Tara Strong (Twilight Sparkle). The Hub, June 2015.

\section{Comic books}

COOK, Katie, and Andy PRICE. “Neigh Anything, part 1." My Little Pony: Friendship is Magic, no. 11, New York: IDW, September 2013.

COOK, Katie, and Andy PRICE. "Neigh Anything, part 2." My Little Pony: Friendship is Magic, no. 12, New York: IDW, October 2013.

COOK, Katie, and Andy PRICE. "Return of Queen Chrysalis, part 2." My Little Pony: Friendship is Magic, no. 2, New York: IDW, January 2013.

\section{Film}

My Little Pony: Equestria Girls. Dir. Jason Thiessen. Written by Meghan McCarthy. With Tara Strong (Twilight Sparkle). Studio B / Hasbro, 2013.

\section{Secondary sources}

AMIDI, Amid. "The End of the Creator-Driven Era in TV Animation." Cartoon Brew, 19 October 2010, www.cartoonbrew.com/ideas-commentary/the-end-of-the-creator-driven-era-29614.html. Accessed 19 April 2018.

BUCKINGHAM, David. After the Death of Childhood: Growing up in the Age of Electronic Media. Cambridge: Polity Press, 2000.

BURDFIELD, Claire. "Finding Bronies-The Accidental Audience of My Little Pony: Friendship is Magic." Journal of Popular Television, vol. 3, no. 1, 2015, p. 128-124.

CIDER FLOAT. "Am I the only one that thought Rainbow Dash was a boy in the beginning?" MLP Forums, 23 November 2015, mlpforums.com/topic/142503-am-i-the-only-one-that-thought-rainbow-dash-was-a-boy-in-thebeginning.

Accessed 30 June 2018.

CODER BRONY. 2014 State of the Herd Report. 21 March 2014, herdcensus.com/2014\%20STATE\%200F\%20THE\%20HERD\%20REPORT.pdf. Accessed 19 April 2018.

CONNELLY, Sherilyn. Ponyville Confidential: The History and Culture of My Little Pony, 1981-2016. New York: McFarland, 2017.

CROME, Andrew. “Meet the 'Bronies': Adult Fans Giving My Little Pony a Marketing Headache.” The Conversation, 6 October 2017,

theconversation.com/meet-the-bronies-adult-fans-giving-my-little-pony-a-marketing- 
headache-85226.

Accessed 19 April 2018.

FAUST, Lauren. "My Little NON-Homophobic, NON-Racist, NON-Smart-Shaming Pony: A Rebuttal.” Ms. Magazine, 24 December 2010, msmagazine.com/blog/2010/12/24/my-little-non-homophobic-non-racist-non-smart-shamingpony-a-rebuttal.

Accessed 19 April 2018.

Federal Communications Commission. "Children's Educational Television.” Federal Communications Commission, 6 November 2017, www.fcc.gov/consumers/guides/childrens-educational-television. Accessed 19 April 2018.

FYRE-FLYE [Lauren Faust]. “FAQ.” DeviantArt, 27 December 2011, fyre-flye.deviantart.com/journal/FAQ-276161988.

Accessed 19 April 2018.

GREENFIELD, Patricia Marks, Emily YUT, Mabel CHUNG, Deborah LAND, Holly KREIDER, Maurice PANTOJA, and Kris HORSLEY. "The Program-Length Television Commercial: A Study of the Effects of Television / Toy Tie-ins on Imaginative Play.” Psychology and Marketing, vol. 7, 1990, p. 237-255.

GRIFFITHS, Daniel Nye. "Friendship is Massive-Ponies, Internet Phenomena and Crossover Audiences." D Nye Everything, 27 September 2011, www.danielnyegriffiths.org/2011/09/friendship-is-money-ponies-internet.html. Accessed 19 April 2018.

HASBRO. 2014 Annual Report. 26 February 2015, wayback.archive-it.org/all/20170707002741/http://files.shareholder.com/downloads/HAS/ 4752457564x0x819559/8A09F66A-4137-45A9-88BA-C16F08E1AF90/ Annual_Report_Website_FINAL.pdf. Accessed 19 April 2018.

HAUTAKANGAS, Mikko. "It's OK to be Joyful? My Little Pony and Brony Masculinity." Journal of Popular Television, vol. 3, no. 1, 2015, p. 111-118. Ingenta Connect.

HELJAKKA, Katriina. "From Toys to Television and Back: My Little Pony Appropriated in Adult Toy Play." Journal of Popular Television, vol. 3, no. 1, 2015, p. 99-109. Ingenta Connect.

HIX, Lisa. "My Little Pony Smackdown: Girls vs. Bronies.” Collectors Weekly, 28 June 2012, www.collectorsweekly.com/articles/my-little-pony-smackdown-girls-vs-bronies. Accessed 19 April 2018.

HOUSE, Kelly. “Meet ‘Bronies'-Grown Men Who Are Fans of My Little Pony.” The Oregonian, 17 September 2011, www.oregonlive.com/entertainment/index.ssf/2011/09/seriously_my_little_pony_grown.html. Accessed 19 April 2018.

"Hub TV Network Scores Record High Audience with Outstanding Performance of Special Royal Wedding of the Year on 'My Little Pony Friendship is Magic."' Investor Hasbro, 24 April 2011, web.archive.org/web/20120428122810/http:/investor.hasbro.com/releasedetail.cfm? ReleaseID=666931. Accessed 19 April 2018.

ILLUSTRIOUS Q. “BABSCon Interview: Lauren Faust (MLP FiM Show Creator).” Equestria Daily, 2 June 2016, 
www.equestriadaily.com/2016/06/babscon-interview-lauren-faust-mlp-fim.html. Accessed 19 April 2018.

JAUSS, Hans Robert. Pour une esthétique de la réception. Translated from the German by Claude Maillard. Paris: Gallimard, 1975.

JENKINS, Henry. Textual Poachers: Television Fans \& Participatory Culture. New York: Routledge, 1992.

JONES, Bethan. "My Little Pony, Tolerance Is Magic: Gender Policing and Brony Anti-fandom." Journal of Popular Television, vol. 3, no. 1, 2015, p. 119-125. Ingenta Connect.

KASHTAN, Aaron. "Multimodality Is Magic: My Little Pony and Transmedia Strategies in Children's Comics." Graphic Novels for Children and Young Adults: A Collection of Critical Essays. Eds. Michelle Ann Abate and Gwen Athene Tarbox. Jackson: University Press of Mississippi, 2017, p. $112-125$.

KEATE, Georgie. “Saddle Up and Meet My Little Pony's Most Unlikely Fans: Bronies.” The Times, 21 October 2017, www.thetimes.co.uk/article/saddle-up-and-meet-my-little-pony-s-most-unlikely-fans-bronies$\lg 39$ tfsjf.

Accessed 19 April 2018.

KENDALL, Lori. “'White and Nerdy': Computers, Race, and the Nerd Stereotype." The Journal of Popular Culture, vol. 44, no. 3, 2011, p. 502-524. Wiley Online Library.

KINDER, Marsha. Playing with Power in Movies, Television, and Video Games: From Muppet Babies to Teenage Mutant Ninja Turtles. Berkeley: University of California Press, 1991.

KIRKLAND, Ewan. “'Little Girls and the Things that They Love': My Little Pony: Friendship Is Magic, Audience, Identity, and the Privilege of Contemporary Fan Culture." Camera Obscura: Feminism, Culture, and Media Studies, vol. 32, no. 2, 2017, p. 89-115. Read Duke University Press.

KLINE, Stephen. Out of the Garden: Toys, TV, and Children's Culture in the Age of Marketing. London: Verso, 1993.

LAPIERRE, Matthew. "Cartoons, Animated." Encyclopedia of Media and Communication. Ed. Marcel Danesi. Toronto: University of Toronto Press, 2013, p. 96-102.

MALAQUAIS, Laurent. The Extremely Unexpected Adult Fans of My Little Pony. BronyDoc, 2013.

POLLACK, Judanne. “'My Little Pony: The Friendship Is Magic' Gains Unexpected AudienceAdults." AdAge, 28 November 2011,

adage.com/article/special-report-americas-hottest-brands/america-s-hottest-brands-ponyfriendship-magic/231166.

Accessed 19 April 2018.

POLLITT, Katha. “The Smurfette Principle.” The New York Times, 7 April 1991, www.nytimes.com/1991/04/07/magazine/hers-the-smurfette-principle.html. Accessed 19 April 2018.

RIBARD, Dinah, and Michel FOUCAULT. 1969 : Michel Foucault et la question de l'auteur : qu'est-ce qu'un auteur? Paris: Honoré Champion, 2019.

ROBERTSON, Venetia Laura Delano. "Of Ponies and Men: My Little Pony: Friendship Is Magic and the Brony Fandom." International Journal of Cultural Studies vol. 17, no. 1, Jan. 2014, p. 21-37. Sage journals. 
S.A. "Interview with Lauren Faust." Horse News, 24 April 2016, www.horse-news.net/2016/04/interview-with-lauren-faust-4chan-girls.html. Accessed 19 April 2018.

SAINTCHESHIRE. “A Word about Bronies.” Tumblr, 2014.

saintcheshire.tumblr.com/post/83484957890/a-word-about-bronies.

Accessed 21 August 2014.

STEINBERG, Shirley S., and KINCHELOE, Joe L. "Introduction: Kinderculture, Information Saturation, and the Socioeducational Positioning of Children." Kinderculture: The Corporate Construction of Childhood. Eds. Shirley R. Steinberg and Joe L. Kincheloe. Boulder: Westview, 2004, p. 1-48.

TEKARAMITY. “Exclusive Season 1 Retrospective Interview with Lauren Faust.” Equestria Daily, 16 September 2011, www.equestriadaily.com/2011/09/exclusive-season-1-retrospective.html. Accessed 19 April 2018.

VALIENTE, Christian, and Xeno RASMUSSON. "Bucking the Stereotypes: My Little Pony and Challenges to Traditional Gender Roles." Journal of Psychological Issues in Organizational Culture, vol. 5, no. 4, 2015, p. 88-87. Wiley Online Library.

VARA, Vauhini, and Ann ZIMMERMAN. “Hey, Bro, That's My Little Pony! Guys' Interest Mounts in Girly TV Show." The Wall Street Journal, 5 November 2011, www.wsj.com/articles/SB10001424052970203707504577012141105109140.

Accessed 19 April 2018.

WALL, Barbara. The Narrator's Voice: The Dilemma of Children's Fiction. New York: St Martin's Press, 1991.

WATERCUTTER, Angela. “My Little Pony Corrals Unlikely Fans Known as Bronies.” Wired, 9 June 2011, www.wired.com/2011/06/bronies-my-little-ponys. Accessed 19 April 2018.

WOO, Benjamin. Getting a Life: The Social Worlds of Geek Culture. Montreal \& Kingston: McGillQueen's University Press, 2018.

\section{NOTES}

1. In this article, I focus mostly on the early days of Generation 4, when the fandom was formed. My corpus spans the first two seasons of the show (2011-2012), in which Lauren Faust was actively involved. I also surveyed the first twelve issues of the comics created around the same period (2012-2013) by Andy Price and Katie Cook. The creative team changed with issue 13, as did that of the TV show during Season 3. An extended corpus (spanning all nine seasons and the various comics spin-offs) would no doubt have led to different findings, notably in terms of authorial involvement (see infra).

2. Many were intrigued in particular by the possible implications regarding the Bronies' gender, sexuality and sexual tastes. I will not be addressing these concerns in the present article; however, for the record, one survey suggests that within the Brony community in 2014, 3 percent identified as transgender, and 15 said they were bi- or homosexual (Coder Brony). 20 percent of Bronies were also involved in the furry fandom, which may or may not involve a taste for anthropomorphic animal pornography. 
3. Prominent examples include Wired article "My Little Pony Corrals Unlikely Fanboys Known as 'Bronies"' (Watercutter n.p.), the Times piece entitled "Saddle up and Meet My Little Pony's Most Unlikely Fans: Bronies" (Keate n.p.), and of course Laurent Malaquais' documentary film Bronies: The Extremely Unexpected Adult Fans of My Little Pony.

4. The series abandoned that label with season 2, possibly as a reaction to the growing diversity of its audience.

5. "Somepony" is the equivalent of "somebody" in the show, hence the spelling.

6. One example among many would be that of the toy-fancying giant cave troll in "Return of Queen Chrysalis, part 2", who is much larger than the protagonists and tries to brush their hair, as if they were My Little Pony dolls (Cook and Price, 2013c 4). The fact that the word "trolls" is also used for people who post intentionally abrasive content on the Internet is probably part of the joke.

\section{ABSTRACTS}

Popular and academic discussions of My Little Pony: Friendship is Magic often tend to contrast the "expected audience" of very young girls with an adult, mostly male "unexpected audience." This polarizing view begs the question of what the various agents involved in the production of the series actually expect of their audience, and how such expectations are expressed through the material they produce and the type of behaviors they encourage. I argue that MLP: FiM is in fact the site of a complex combination of expectations (moral, commercial, and otherwise) that create a specific type of audience. Beyond their obvious commercial nature, the MLP: FiM show and comics are tied with ideological and legal concerns regarding the status of children's entertainment, which is expected to protect and educate its audience. Moreover, the creators had their own set of expectations: they set out to question gender stereotypes by creating quality entertainment for girls that presented independence, solidarity, and individual development as positive values. The desire to reappraise girls' entertainment helped create a franchise that was in fact transgenerational and encouraged different modes of participation, thus creating the conditions for the emergence of an older, more media-savvy fan audience.

La franchise My Little Pony: Friendship is Magic est célèbre pour son public « inattendu », un fandom composé en grande partie d'hommes adultes, et qui semble contraster fortement avec son public « cible» (les petites filles). Cette vision clivée invite à s'interroger sur les attentes et intentions des différents agents impliqués dans la production des récits, sur la façon dont ces attentes se manifestent et sur le type de comportements encouragés. En effet, MLP: FiM se situe à la convergence de nombreuses injonctions (commerciales, morales, idéologiques etc.) visant à construire un public spécifique. Les comics et dessins animés MLP: FiM sont une commande d'Hasbro visant à stimuler ses ventes de jouets pour filles, mais ils sont également tributaires de contraintes juridiques et idéologiques liées à leur statut de divertissement enfantin, destiné à préserver et éduquer leur jeune public. Par ailleurs, les équipes impliquées dans le développement des récits de MLP: FiM possèdent leurs propres attentes; en particulier, il s'agit de remettre en question les stéréotypes de genre véhiculés par l'industrie du divertissement pour filles en inculquant à ces dernières des valeurs d'indépendance, de solidarité et de développement personnel. Cette prise de position est en fait au cœur de l'attraction 
transgénérationnelle de MLP: FiM et constitue le terreau dans lequel une communauté de fans plus âgés s'est enracinée, développant de nouveaux modes de consommation.

\section{INDEX}

Mots-clés: My Little Pony: Friendship is Magic, série télévisée, comics, transmédia, Hasbro, jouets, audiences, modes de consommation, genre, enfance, fans

Keywords: My Little Pony: Friendship is Magic, TV series, comics, transmedia, Hasbro, toys, audiences, consumption patterns, gender, childhood, Fan Studies

\section{AUTHOR}

\section{ISABELLE LICARI-GUILLAUME}

Université Nice - Sophia Antipolis, France 